\title{
Virtual disjunct eddy covariance measurements of organic compound fluxes from a subalpine forest using proton transfer reaction mass spectrometry
}

\author{
T. G. Karl ${ }^{1}{ }^{*}$, C. Spirig ${ }^{1,2}$, J. Rinne ${ }^{1,3}$, C. Stroud ${ }^{1}$, P. Prevost ${ }^{1}$, J. Greenberg ${ }^{1}$, R. Fall ${ }^{4}$, and A. Guenther ${ }^{1}$ \\ ${ }^{1}$ National Center for Atmospheric Research, Boulder, Colorado, USA \\ ${ }^{2}$ Eidg. Forschungsanstalt für Agrarökologie und Landwirtschaft, Zürich, Switzerland \\ ${ }^{3}$ now at: Centre National de Recherches Meteorologiques, Toulouse, France \\ ${ }^{4}$ University of Colorado, Boulder, Colorado, USA \\ * present address: ACD, NCAR, PO 3000, Boulder, CO, 80307, USA
}

Received: 17 May 2002 - Published in Atmos. Chem. Phys. Discuss.: 23 July 2002

Revised: 16 October 2002 - Accepted: 18 October 2002 - Published: 29 October 2002

\begin{abstract}
A 'virtual' disjunct eddy covariance (vDEC) device was tested with field measurements of biogenic VOC fluxes at a subalpine forest site in the Rocky Mountains of the USA. A PTR-MS instrument was used as the VOC sensor. Daily peak emission fluxes of 2-methyl-3-buten-2-ol (MBO), methanol, acetone and acetaldehyde were around $1.5,1,0.8$ and $0.4 \mathrm{mg} \mathrm{m}^{-2} \mathrm{~h}^{-1}$, respectively. High pass filtering due to long sampling lines was investigated in laboratory experiments, and suggested that VOC losses in PTFA lines are generally governed by diffusion laws. Memory effects and surface reactions did not seem to play a dominant role. Model estimates of MBO fluxes compared well with measured fluxes. The results also suggest that latent heat and sensible heat fluxes are reasonably well correlated with VOC fluxes and could be used to predict variations in VOC emissions. The release of MBO, methanol, acetone and acetaldehyde resulted in significant change of tropospheric oxidant levels and a $10-40 \%$ increase in ozone levels, as inferred from a photochemical box model. We conclude that vDEC with a PTR-MS instrument is a versatile tool for simultaneous field analysis of multiple VOC fluxes.
\end{abstract}

\section{Introduction}

Interest in reliable quantification of organic trace compounds released from terrestrial ecosystems stems from their impact on oxidants levels such as ozone $\left(\mathrm{O}_{3}\right)$ and hydroxyl radicals (HO) and on secondary organic aerosol formation (R. Atkinson, 1994). Oxygenated species such as acetone or methanol can also influence the $\mathrm{HO}_{\mathrm{x}}$ budget in the upper troposphere (Singh et al., 1995). In addition, acetone and acetaldehyde

Correspondence to: T. G. Karl (tomkarl@ucar.edu) can be converted to acetylperoxy radicals by atmospheric oxidation and lead to formation of PAN (peroxyacetic nitric anhydride) type compounds, which act as relatively long-lived temporary reservoirs for nitrogen oxides $\left(\mathrm{NO}_{\mathrm{x}}\right)$. Volatile organic compounds (VOCs), together with carbon dioxide also influence the atmospheric radiative balance, temperature and precipitation patterns (Granier et al., 1998). In order to quantitatively understand tropospheric chemistry it is a necessary prerequisite to have reliable measurements of VOC fluxes. As indicated by model calculations, $1150 \mathrm{Tg}$ of carbon is emitted into the atmosphere every year in the form of biogenic VOCs from vegetation (Guenther et al., 1995). However there are still large uncertainties in estimates of the magnitude of VOC fluxes in various ecosystems and oxygenated VOC fluxes are particularly uncertain. Kesselmeier (2001) found both uptake and emission of some aldehydes, however states that "further studies are needed for generalization of the exchange of these and potentially also for other compounds." Earlier studies used plant enclosures (Koenig et al., 1995), gradient techniques (Guenther et al., 1996), and more recently relaxed eddy accumulation techniques (REA), to measure above-canopy fluxes of VOC at several field sites and improve our understanding of the biosphere-atmosphere exchange of these compounds (Schade and Goldstein, 2001; Baker et al., 2001). The main difficulties in measuring fluxes with these techniques arise from memory effects, gas chromatographic challenges (e.g. humidity effects) and problems in sampling, such as compound conversion and surface reactions with ozone. Various methods for measuring trace gas exchange, including enclosure, surface layer flux and mixed boundary layer techniques have been reviewed by Dabberdt et al. (1993) and more recently by Guenther (2002). Ecosystemscale BVOC fluxes are commonly measured by 
the surface layer gradient and the relaxed eddy accumulation method. The gradient technique uses the average concentration difference (e.g. $30 \mathrm{~min}$ ) measured at two or more heights above the vegetation canopy. The flux is calculated in analogy to Fick's 1st law. The turbulent exchange coefficient (K) needed for the flux calculation is either obtained by using the concentration of a tracer, e.g. $\mathrm{H}_{2} \mathrm{O}$ or $\mathrm{CO}_{2}$, (modified Bowen-ration technique, e.g. Goldstein et al., 1996), or by surface layer similarity theories (e.g. Fuentes et al., 1996). Common criticism for gradient flux measurements is that (1) the various sampling heights have different footprint characteristics and (2) that photochemical destruction of reactive compounds (e.g. isoprene, MBO) can bias the 'observed' flux. The relaxed eddy accumulation method measures the flux at only one location above the canopy. Air is sampled into two reservoirs for the length of the averaging period ( 30 min- $1 \mathrm{~h}$ ) depending on the sign of the vertical wind velocity. The flux is obtained by using the concentration difference between up-draft and down-draft reservoirs (Businger and Oncley, 1990) and an empirical exchange coefficient, which has to be obtained either by theoretical considerations (e.g. Baker et al., 1992) or similarity with another scalar (e.g. Baker et al., 1999). The advantage of gradient and relaxed eddy accumulation methods is that they do not require fast response analyzers and can rely on off-line laboratory analysis of air samples. Disadvantage is that they are indirect techniques (require empirical parameterisations), which limits their application to certain sites and conditions (Dabberdt et al., 1993). In addition, post-processing of eddy accumulation data (e.g. coordinate transformation) is not possible, and this also puts some constraints on canopy level flux measurements at non-ideal sites which are governed by slope and drainage winds.

Eddy covariance (EC) is the most direct method for flux measurements of atmospheric constituents in the surface layer. As a substantial part of the flux is carried by small eddies, it is important to be able to measure fast variations of vertical wind velocity and trace gas concentration. With traditional eddy covariance systems (continuous sampling mode) the sample rate is generally higher than $5 \mathrm{~Hz}$, thus requiring fast-response analyzers and data acquisition systems. These requirements have restricted the use of this method for trace gas flux measurements. Only recently have the first VOC sensors been introduced for monitoring fast VOC fluctuations, as in the case of isoprene using a chemiluminescence system (Guenther and Hills, 1998), and for acetone, ammonia, nitric acid and formic acid, using an atmosphericpressure-ionization mass spectrometer (Shaw et al., 1998). Nevertheless, these sensors are limited to a few chemical species, and a detection system that is able to measure a broader range of compounds (e.g. terpenes, aldehydes and alcohols) is desired. We have recently expanded the capabilities of Proton Transfer Reaction Mass Spectrometry (PTRMS) to perform direct eddy covariance measurements of a wider suite of compounds (Karl et al., 2000a, b; 2001).
Disjunct eddy covariance (DEC) can be regarded as a variant of the eddy covariance (EC) and has recently been implemented for trace gas flux measurements (Rinne et al., 2001). Air samples, taken almost instantaneously $(\sim 0.1 \mathrm{~s})$ and separated by a long time interval $(\Delta t=10-30 \mathrm{~s})$, are analyzed by a relatively slow analyzer (time of analysis $<\Delta t$ ) and create a subset of the continuous high frequency time series. Since the flux is defined as the covariance of eddy components of the vertical wind velocity $\left(w^{\prime}\right)$ and the trace gas concentration $\left(c^{\prime}\right)$, the subset can be used to estimate the flux:

$$
F_{c}=\frac{1}{t_{2}-t_{1}} \int_{t_{1}}^{t_{2}} w^{\prime}(t) c^{\prime}(t) d t \approx \frac{1}{N} \sum_{i=1}^{N} w^{\prime}(i \Delta t) c^{\prime}(i \Delta t)
$$

The influence of small scale eddies is taken into account as long as air samples are grabbed quickly $(\sim 0.1 \mathrm{~s})$. Even though some systematic and random errors are introduced for each flux value, it is a direct flux measurement technique, which does not rely on parameterizations such as the gradient and relaxed eddy covariance methods (Dabbert et al., 1993; Lenschow et al., 1994; Rinne et al., 2001). The disjunct eddy sampling approach has also been applied for true eddy accumulation (Rinne et al., 2000).

A quadrupole mass spectrometer (QMS) as used for the PTR-MS puts severe time constraints for direct $10 \mathrm{~Hz}$ measurements, since only a very limited set of compounds can be measured 'simultaneously'. If 20 compounds of interest are to be scanned at $10 \mathrm{~Hz}$, an integration time (dwell) of $0.5 \mathrm{~ms}$ is needed. The minimum dwell is on the order of $1 \mathrm{~ms}$, and additional time $(\sim 1 \mathrm{~ms})$ is required for changing the QMS settings by switching from one $\mathrm{m} / \mathrm{z}$ (mass to charge) ratio to the next, making it impossible to perform an exact $10 \mathrm{~Hz}$ measurement for more than a few compounds. This led to the design of a disjunct sampler used together with a PTR-MS instrument that had a $1 \mathrm{~Hz}$ sampling rate, as described by Rinne et al. (2001). Here, the concept of disjunct eddy covariance (DEC) has been adopted. Air is purged continuously through the PTR-MS, while scanning through all compounds of interest. This leads to a disjunct time series of $\sim 1 \mathrm{~s}$ separated samples, if for example 10 compounds are chosen. The virtual disjunct eddy covariance (vDEC) method does not require a physical grab sampler and makes the inlet system much simpler. In this paper we will describe several implications for vDEC and direct eddy covariance sampling at tower sites and present data measured at a subalpine forest in the Rocky Mountains.

\section{Experimental}

\subsection{Site}

VOC fluxes were measured at the Niwot Ridge AmeriFlux site in the Roosevelt National Forest in the Rocky Mountains of Colorado, USA. $\left(40^{\circ} 1^{\prime} 58.4^{\prime \prime} \mathrm{N}, 105^{\circ} 32^{\prime} 47.0^{\prime \prime} \mathrm{W}\right)$, 
approximately $8 \mathrm{~km}$ east of the continental divide. The site is characterized by an east-west slope of $\sim 6^{\circ}$ (a $\sim 4.4^{\circ}$ rotational angle was inferred from our sonic data) with a fetch of $\sim 2 \mathrm{~km}$ to the west and $300-400 \mathrm{~m}$ to the east, where the slope increases to $\sim 13^{\circ}$. The mixed coniferous forest mainly consists of subalpine fir (Abies lasiocarpa 35\%), lodgepole pine (Pinus contorta 43\%), and Engelmann spruce (Picea engelmannii 22\%), with small amounts of aspen (Populus tremuloides). The measured leaf area index (LAI) was 3.8$4.2 \mathrm{~m}^{2} \mathrm{~m}^{-2}$ (Turnipseed et al., 2002). A late frost in May 2001 damaged many aspen leaves, which did not recover by June. Summertime meteorology is characterized by valleymountain flow, with buoyancy driven upslope flow from the east in the afternoon, which occasionally brings more polluted air masses from the Denver Metropolitan area to the site. The two predominant wind directions are centered on $105^{\circ}$ and $270^{\circ}$ (Turnipseed et al., 2002). The 14-17 June sampling period was characterized by prevailing winds from westerly directions $\left(\sim 281 \pm 10^{\circ}\right)$.

\subsection{VOC Sampling}

A detailed description of the PTR-MS instrument is given elsewhere (Lindinger et al., 1998). Briefly, $\mathrm{H}_{3} \mathrm{O}^{+}$ions are used to ionize volatile organic compounds (VOC) via proton transfer reactions. Since any VOC having a higher proton affinity than water can be ionized by $\mathrm{H}_{3} \mathrm{O}^{+}$reported concentrations have to be regarded as upper limits. However as demonstrated, potential interferences for several VOCs (such as acetone, acetaldehyde and methanol) are either very small or non-existent (Karl, 2001a; de Gouw et al., 2002). The value for $E / N$ ( $E$ being the electric field strength and $N$ the buffer gas density) in the drift tube was kept at about 123 Townsend (Td) which is high enough to avoid strong clustering of $\mathrm{H}_{3} \mathrm{O}^{+}$ions with water and thus a humidity dependent sensitivity. The sensitivity of the PTR-MS instrument during this study was typically on the order of $70 \mathrm{~Hz} / \mathrm{ppbv}$ (counts per second per ppbv) for acetone and $50 \mathrm{~Hz} / \mathrm{ppbv}$ for methanol at $2.3 \mathrm{mbar}$ buffer gas pressure with a reaction time of $110 \mu \mathrm{s}$ and $3-4 \mathrm{MHz} \mathrm{H}_{3} \mathrm{O}^{+}$ions, and thus inferred a signal to noise ratio of $60 \%$ at a concentration of 20 pptv and a $2 \mathrm{~s}$ integration time.

The error variance $\sigma_{f}$ for eddy covariance measurements, including the error due to the finite length of a sample $S$ and the contribution due to a white noise variance $\sigma_{n c}^{2}$, can be formulated as,

$\sigma_{f}^{2}=\frac{\sigma_{w}^{2}}{S} \cdot\left(4 \sigma_{c}^{2} l_{w s}+\sigma_{n c}^{2} \Delta x\right)$,

with $\Delta x$ being the distance between samples, $l_{w s}$ the integral length scale, $\sigma_{w}$ the standard deviation of the vertical wind velocity and $\sigma_{c}$ the standard deviation of the observed concentration. This imposes a flux detection limit of:

$\sigma_{n c}^{2} \leq \frac{4 \sigma_{c}^{2} l_{w s}}{\Delta x}$

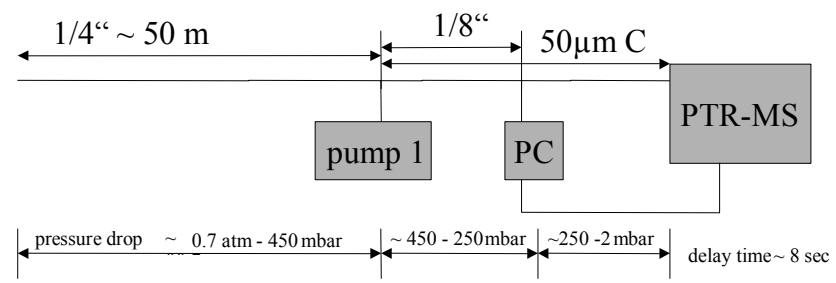

Fig. 1. Schematic sample inlet, PC (pressure controller), pump 1 (Vaccuubrand MD4), $50 \mu \mathrm{m} \mathrm{C}$ (desactivated glass capillary).

(Lenschow and Kristensen, 1985). Taking sensitivities in the range of $50-200 \mathrm{~Hz} / \mathrm{ppbv}$, ambient mixing ratios around $500 \mathrm{pptv}$ and integral timescales $l_{w s}$ between 1.8 and $20 \mathrm{~s}$, we derive theoretical flux detection limits between $0.55-1.8 \times$ $10^{-8} \mathrm{~g} \mathrm{~m}^{-2} \mathrm{~s}^{-1}$.

Figure 1 shows the vDEC sampling setup. A flow rate of $15 \mathrm{l} / \mathrm{min}$ was pumped through a $50 \mathrm{~m}$ tube (i.d. 1/4") (VACUUBRAND, MD4) resulting in a pressure drop of $450 \mathrm{mbar}$ at its end. The $1 / 4^{\prime \prime}$ sampling line was interfaced to the PTRMS system with a pressure controlled $1 / 8^{\prime \prime}$ line. A $3 \mathrm{~m}$ long desactivated glass capillary $(50 \mu \mathrm{m})$ was connected to the drifttube reducing the pressure to $2.3 \mathrm{mbar}$ and reached as far as the front end of the $1 / 8^{\prime \prime}$ line. This setup assured a fast response time and minimised memory effects due to long residence times. The QMS was operated in a selective ion mode cycling through 10-20 compounds of interest at $0.2 \mathrm{~s}$ integration time and producing a 'virtual' disjunct time series with $\Delta x \sim 2-4 \mathrm{~s}$. Integral time scales $l_{w s}$ in this study were estimated to be $\sim 10-20 \mathrm{~s}$, by identifying the peak of the normalized $w^{\prime} T^{\prime}$ cospectrum. This gives a quasi independent sample population of $T_{a v} / l_{w s} \sim 1800 / 10=180\left(T_{a v}\right.$ : averaging time). With $\sim 450-900$ samples per averaging period $\left(\Delta x / l_{w s} \sim 0.2\right)$ flux errors due to disjunct sampling are $1.1 \%$ or less (Appendix (4), Lenschow et al., 1994).

Five species, namely methanol (mass $33^{+}$), acetaldehyde (mass $45^{+}$), acetone (mass $59^{+}$), 2-methyl-3-buten-2ol $(\mathrm{MBO})\left(\operatorname{mass} 87^{+} / 69^{+}\right.$) and isoprene (mass $69^{+}$) were targeted for this study. Isoprene and MBO fluxes both occur at the Niwot Ridge Flux Tower (Goldan et al., 1993; Baker et al., 2001; Harley et al., 1996) making it difficult to quantify the individual contribution of either compound by PTR-MS. Several other potential interferences such as unsaturated C5alcohols and C5-aldehydes, which can be released by freezing vegetation and dehydrate partially during proton transfer, can also interfere on mass $69^{+}$(Karl et al., 2001, 2000a; de Gouw et al., 2002). Since a small fraction $(\sim 25 \%)$ of the MBO does not fragment, but shows a signal on the parent

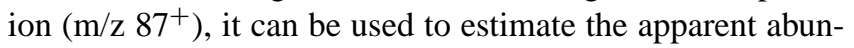
dance of MBO relative to isoprene. Significant interference from a methanol water or isoprene water cluster can be excluded due to the high value of $E / N$. A standard of MBO was released next to the sampling inlet at the top of the tower. Figure 2 (panel 2) shows the distribution of the MBO stan- 


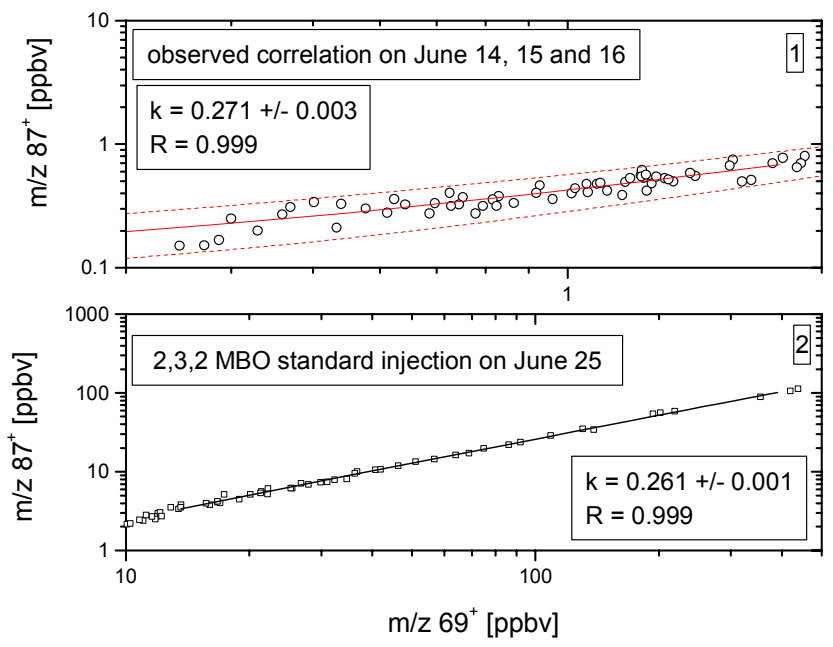

Fig. 2. Panel 1: Observed correlation between $\mathrm{m} / \mathrm{z} 69^{+}$and $\mathrm{m} / \mathrm{z}$ $87^{+}$on $14,15,16$ June the red solid line is the fit line and dashed lines represent the $1-\sigma$ interval due to counting statistics at $0.2 \mathrm{~s}$; Panel 2: fragmentation of a 2,3,2 MBO standard injected at the top of the flux tower on 25 June.

dard yielding $26.1 \%$ and $73.9 \%$ abundance on mass $87^{+}$and $69^{+}$, respectively. The observed ratio $(30 \mathrm{~min}$ average) between $14-16$ June was $27.1 \%$ and $72.9 \%$ for $\mathrm{m} / \mathrm{z} 87^{+}$and $69^{+}$(panel 1). The dashed lines indicate the $1-\sigma$ confidence intervals based on counting statistics. All the observed datapoints fall within the expectation value. The good agreement supports the idea that mainly MBO was monitored at mass $69^{+}$. Additional cartridge samples (using TENAX and Carbosieve as adsorbents) with subsequent GC-FID analysis confirmed these results and showed that the observed MBO concentrations were typically $2-8$ times higher than isoprene. This is supported by the fact that leaves from the dominant isoprene emitting species in the vicinity, (aspen), had not recovered from an early frost event in 2001. Cartridge samples were stored at low temperatures (Baker et al., 2001) to minimise MBO to isoprene conversion. However it has to be noted that the measured MBO concentrations therefore represent a lower limit; relatively low $\mathrm{MBO}$ /isoprene ratios were identified with cartridges stored relatively long and/or at higher temperatures. No significant abundance of C5-aldehydes or alcohols was detected by the GC-FID system. The upper limit of pentenols + pentanal was inferred to be $<5 \%$. GC-analysis also helped to identify and verify other observed VOC mixing ratios, such as acetone, where interference from propanal could bias acetone (mass $59^{+}$) concentrations measured by PTR-MS. It appears that no significant interference for methanol, acetaldehyde and acetone existed and that more than $85 \%$ of the observed signal exhibiting mass $69^{+}$could be attributed to MBO.

\subsection{Wind tunnel setup}

In order to test the response time of the PTR-MS instrument and evaluate damping effects in long Teflon lines, experiments were carried out in a small wind tunnel (i.d. $60 \mathrm{~cm}$, length $4 \mathrm{~m}$ ). VOC fluctuations in the tunnel were created by placing 2 petri dishes (i.d. $15 \mathrm{~cm}$ ), sealed with a semipermeable membrane and containing one or more compounds, on the floor. The wind tunnel was operated at a speed of $\sim 3 \mathrm{~m} \mathrm{~s}^{-1}$, with the intake of the sampling tube (1/4" PFA Teflon) located at $z \sim 0.15 \mathrm{~m}$ above the floor and roughly $\sim 0.2 \mathrm{~m}$ downwind. The Reynolds number ( $\mathrm{Re})$ of the wind tunnel at these conditions was $\sim 1.1 \times 10^{5}$, sufficient for the existence of an inertial subrange (Tennekes and Lumley, 1972). Standard surface layer spectral behavior (Kaimal et al., 1972) predicts that the obtained spectra make a transition from a roughly constant value to the inertial subrange $-5 / 3$ power law at a frequency of $\sim 0.2 u_{t} / z=4 \mathrm{~Hz}$, in a slightly stable surface layer. VOC fluctuations observed in the internal boundary layer were observed to make a transition around $2-3 \mathrm{~Hz}$ close to the predicted fall off. The setup for the PTR-MS sample inlet was essentially the same as for the flux measurements (see Sect. 2.2, Fig. 1). However the $1 / 4^{\prime \prime}$ Teflon line was only $\sim 2 \mathrm{~m}$ long for the base case and $30 \mathrm{~m}$ long for the reference measurements. In addition flow rates (residence times in the line) were controlled between 1-401 $\mathrm{min}^{-1}$. The minimum line length $L_{m}$ of $\sim 2 \mathrm{~m}$ was of sufficient length for the internal boundary layer in the tube $(r \sim 0.0030 \mathrm{~m})$ to grow out from the surface to the center of the sampling tube $\left(L_{m} / r \sim 666 \gg 200\right)$ (Eckert and Drake, 1959).

\subsection{Data processing}

Wind and concentration data were recorded on two separate laptop computers that were synchronized in time every day. The datasets were conditioned according to general aspects as discussed by Stull (1988): (1) spike removal, (2) detrending, (3) subtraction of the mean and (4) coordinate transformation to account for the sloped terrain. The delay time at tower sites (depending on the line length) can be on the order of a few seconds $(\sim 8 \mathrm{~s})$ and complicates the flux calculation, since pumping speeds may vary over the course of the day. In the present case, additional timing uncertainty arose from the fact that the wind and concentration data were recorded on two separate computers. For standard $10 \mathrm{~Hz}$ measurements the quadratur spectrum $\left(Q_{w c}\right)$ is a good indicator to assess delay times (Stull, 1988). High correlation will cause a quadratur spectrum that is close to zero. If there is a phase shift, Qwc will show a significant deviation around $1 / t_{d}$ in the direction of the time delay $\left(t_{d}\right)$. This procedure is not available for disjunctly measured time series. In order to estimate the delay time and to synchronize the wind and concentration datasets, a correlation routine was applied similar to that discussed by McMillen (1988). The maxi- 


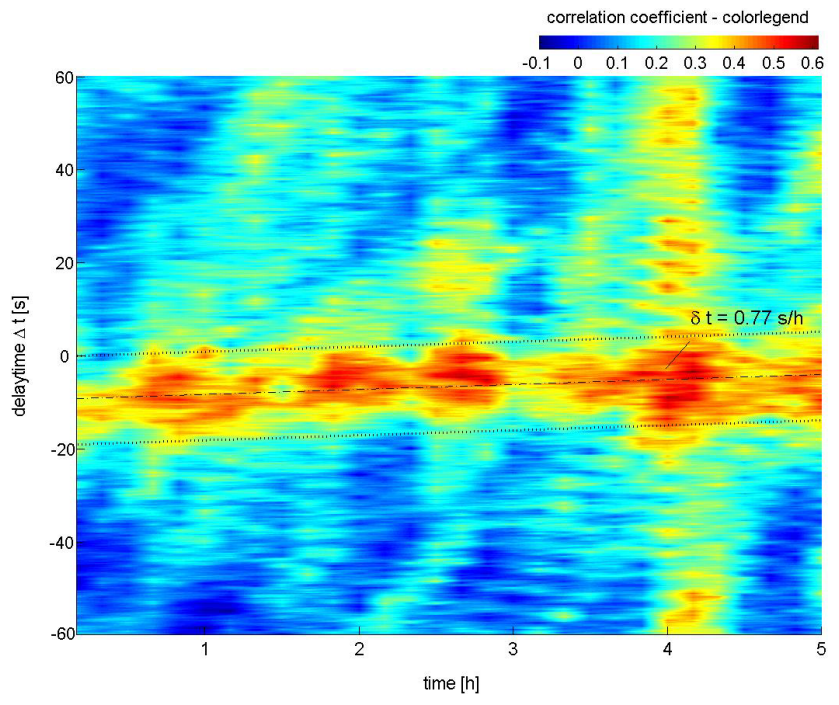

Fig. 3. Correlation coefficients $r_{c w}$ as a function of time shift (= effective delay time) and time since start of the measurement. The two dotted lines show the bandwidth related to the integral time scales measured on that day (10-20s). The time shift varies over the course of the 5 -hour period $(\delta t=0.77 \mathrm{~s} / \mathrm{h})$ due to the fact that two different computers were used for the wind and concentration data acquisition.

mum correlation within $\pm 60 \mathrm{~s}$ was defined to be equal to the delay time plus uncertainties due to possible desynchronized time series. Figure 3 depicts the correlation coefficients $\left(r_{w c}\right)$ between the vertical windspeed (measured at the top of the canopy) and the concentration fluctuation of MBO (delayed measurement at the bottom of the canopy) during the course of a 5-hour period on 16 June and demonstrates that the delay time can be accurately assessed from a disjunct sampled time series. The maximum correlation coefficients rwc were in the range of $0.3-0.6$ and varied slightly over the course of the 5hour period due to timing differences $(\delta t=0.77 \mathrm{~s} / \mathrm{h}$ time shift) between two separate computers used for the data acquisition. The bandwidth of high $r_{c w}$ 's $(\sim 20 \mathrm{~s}-$ indicated by the dotted lines; mean delay time $\pm 10 \mathrm{~s}$ ) is directly related to integral time scales, calculated to be in the range of $\sim 10 \mathrm{~s}$. Non-stationary periods due to upslope drainage winds show high correlation coefficients within almost $\pm 60 \mathrm{~s}$. The presented procedure corrected the difference between the two computer clocks and accounted for a potentially variable delay time in the sampling tube caused by varying pumping speeds. Fluxes were calculated according to,

$F_{c}=\left\langle w^{\prime} c^{\prime}\right\rangle=\frac{1}{n} \cdot \sum_{i=1}^{n} w^{\prime}\left(t_{i}\right) \cdot c^{\prime}\left(t_{i}\right)=r_{w c} \cdot \sigma_{w} \cdot \sigma_{c}$

where $w$ is the vertical wind speed, $c$ the VOC concentration, $\sigma_{w}$ and $\sigma_{c}$ standard deviations of $w$ and $c$, and $r_{w c}$ the correlation coefficient between $w$ and $c$.

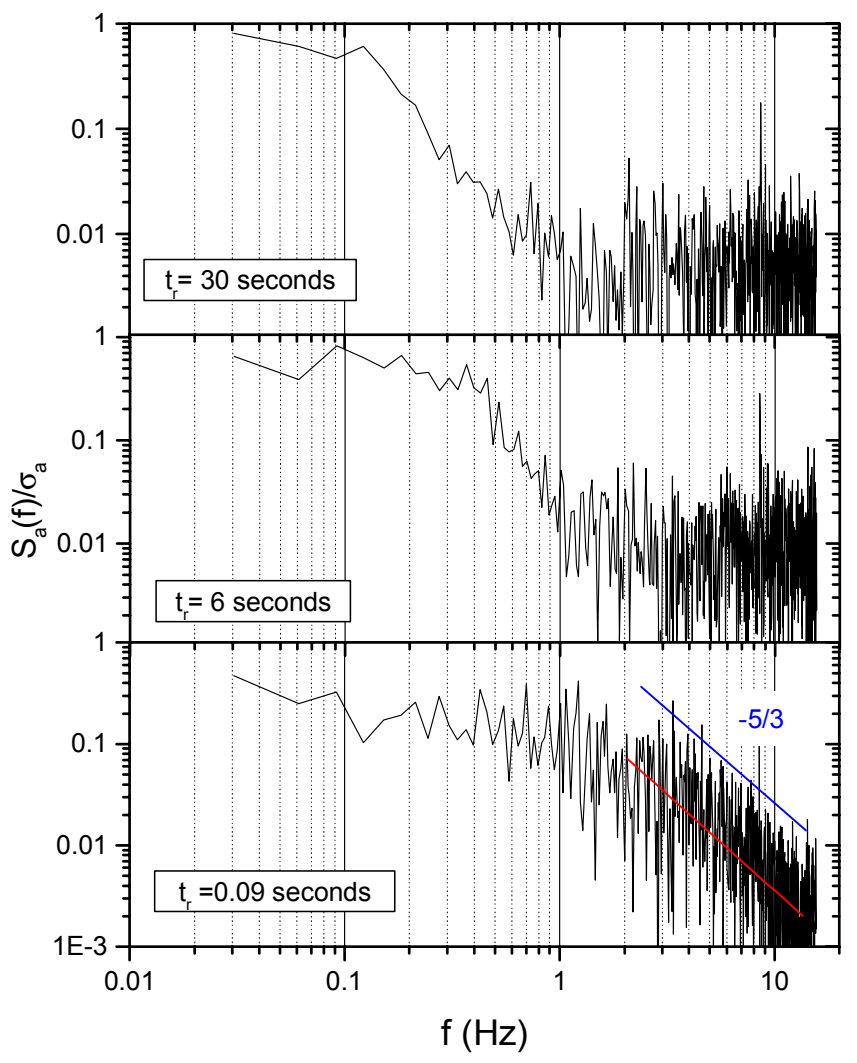

Fig. 4. Spectral behaviour of acetone inferred from a wind tunnel experiment; lower panel: $2 \mathrm{~m}$ PTFA line (i.d. $1 / 4^{\prime \prime}$ ) and $0.09 \mathrm{~s}$ residence time, middle panel: $30 \mathrm{~m}$ PTFA line and $6 \mathrm{~s}$ residence time, upper panel: $30 \mathrm{~m}$ PTFA line and $30 \mathrm{~s}$ residence time.

\section{Results}

\subsection{Laboratory tests}

In the present case where we use a vDEC setup to measure canopy level fluxes, the time constraint for being able to resolve concentration fluctuations around $0.1 \mathrm{~s}$ is not relaxed. As described in Sect. 2.3 we investigated the response time of the PTR-MS in a controlled way by calculating concentration spectra and examining the inertial subrange with an expected $-5 / 3$ slope. This approach proved to be more accurate than injecting a concentration pulse by switching a valve and following its time evolution. These experiments also helped to address the basic question to what extent memory effects of VOCs (chemically more active than for example $\mathrm{CO}_{2}$ or $\mathrm{H}_{2} \mathrm{O}$ ) would bias eddy covariance measurements through long sampling lines.

High-pass filtering in inlet lines was tested by examining the spectral behaviour as a function of line lengths and flow rates. Figure 4 shows the un-smoothed, normalised power spectra for acetone (raw data, upper panel) at different flow speeds $u_{t}$ through a $30 \mathrm{~m} 1 / 4^{\prime \prime}$ PTFA sampling tube together with a reference spectrum (lower panel) obtained through a 


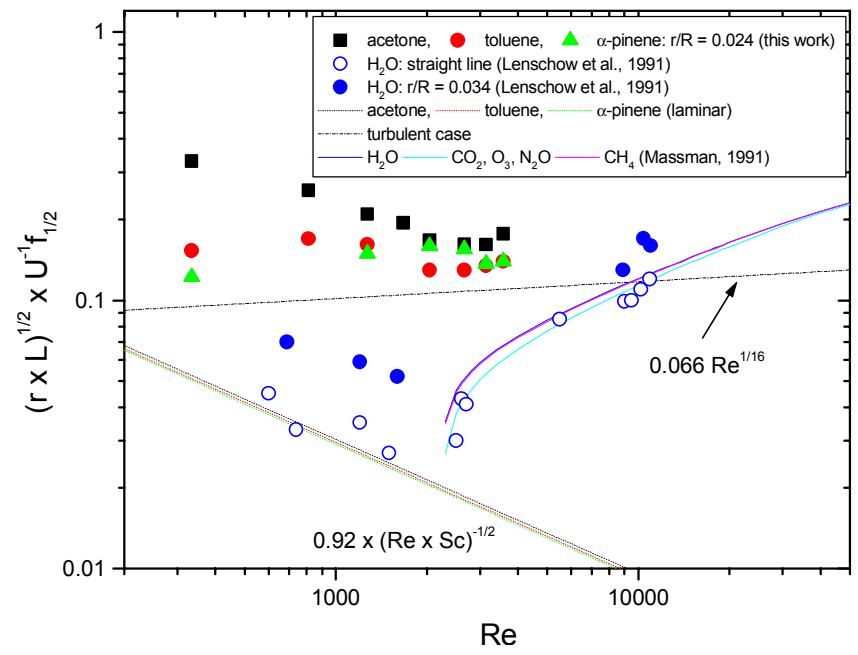

Fig. 5. Normalized half power frequency $\left(f_{1 / 2}\right)$ as a function of Reynolds number for acetone, toluene and $\alpha$-pinene in comparison with theoretical predictions and experimental data for $\mathrm{H}_{2} \mathrm{O}$.

$2 \mathrm{~m}$ line with $0.09 \mathrm{~s}$ residence time. The fitted line through the inertial subrange for the reference spectrum approaches the theoretical prediction of a $-5 / 3$ slope closely up to $10 \mathrm{~Hz}$, showing that the PTR-MS instrument has a time response of at least $100 \mathrm{~ms}$. The frequency $\left(f_{1 / 2}\right)$, where the power spectral intensity is only half of the original signal, was normalised according to $y_{0}=(r \times L)^{1 / 2} \times U^{-1} \times f_{1 / 2}$, with $U$ being the flow speed, $L$ the line length and $r$ the radius. Figure 5 depicts measured half power frequencies for acetone, toluene and $\alpha$-pinene as a function of Reynolds number $(\mathrm{Re})$. Straight lines indicate the attenuation characteristics from the empirical Blasius resistance formula (Eckert and Drake, 1959) for laminar $\left(y_{0} \sim 0.92 /(\mathrm{ReSc})^{1 / 2}\right)$ and turbulent $\left(y_{0} \sim 0.066 \operatorname{Re}^{1 / 16}\right)$ flows as well as results for the transfer function obtained more recently by Massman (1991). Blue circles represent damping effects for $\mathrm{H}_{2} \mathrm{O}$ in a straight line (open circles) and a line with a $90^{\circ}$ elbow bend measured by Lenschow et al. (1991). The fact that our experimental values are slightly higher than the prediction for turbulent conditions is most likely due to the fact that a coiled line was used, which is known to reduce the actual effective turbulent diffusivity. The effect of curvature in tubing typically stabilises the flow so that the flow remains laminar, even at higher Reynolds numbers. McConalogue (1970) predicted that for laminar flow the observed increase of the half power frequency $f_{1 / 2}$ would make the velocity profile more uniform over the tube cross section when compared to Poiseuille flow. This suggests that coiled tubes could actually improve the frequency response. Higher values for acetone could be related to a slightly lower Schmidt number $(\mathrm{Sc} \sim 0.9)$, which could play a role at low Reynolds numbers (more laminar conditions). Memory effects however do not seem to influence the VOC fluctuations to a great extend. The results sug-

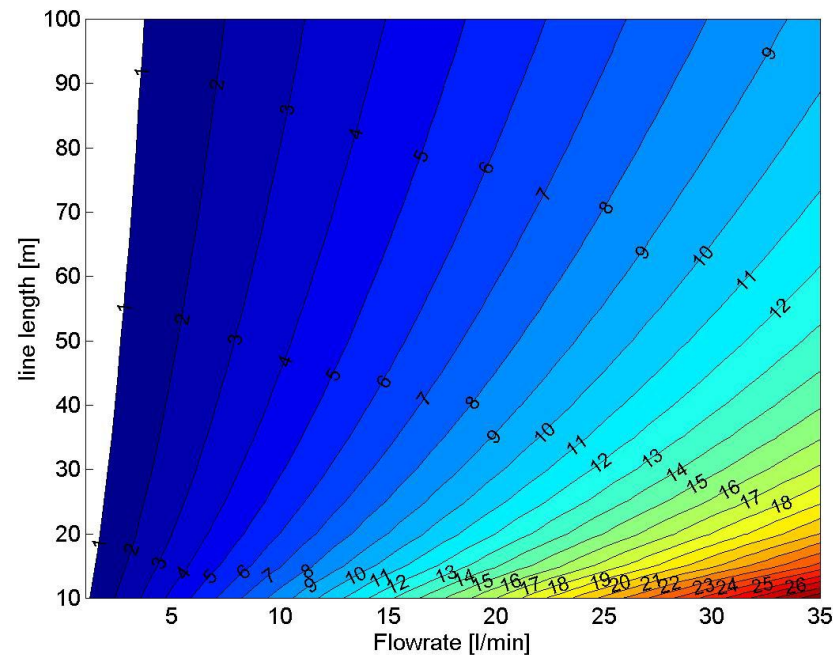

Fig. 6. Effective half power frequency $\left(f_{1 / 2}\right)$ for acetone as a function of line length and flow rate through a PTFA tube (i.d. $1 / 4^{\prime \prime}$ ).

gest that high frequency loss due to diffusion is the most important cause for the observed attenuation. Figure 6 shows a contour plot of the half power frequency as a function of line length and flow rate. Typical conditions in this work involved line lengths up to $50 \mathrm{~m}$ at flow rates around $151 \mathrm{~min}^{-1}$, resulting in $f_{1 / 2}$ around $5.5 \mathrm{~Hz}$. This is high enough to avoid a significant systematic loss for canopy level flux measurements, where typically more than $90 \%$ of the flux is captured at $1 \mathrm{~Hz}$ (Guenther and Hills, 1998).

\subsection{Fluxes}

Figure 7a and $\mathrm{b}$ show measured MBO fluxes together with modelled values. Maximum fluxes for MBO were $\sim 1.5$ and $2 \mathrm{mg} \mathrm{m}^{-2} \mathrm{~h}^{-1}$ on 16 and 17 June, respectively, occurred typically between 12:00 and 14:00 local time (LT), and followed the expected light and temperature patterns. Modelled emissions (based on the EXP96 light and temperature algorithm, Guenther et al., 1999) were calculated assuming a leaf area index (LAI) of $4 \mathrm{~m}^{2} \mathrm{~m}^{-2}$, a biomass density of $720 \mathrm{~g} \mathrm{~m}^{-2}$ and an emission factor of $20 \mu \mathrm{g} \mathrm{gdw}^{-1} \mathrm{~h}^{-1}$ (Guenther et al., 1995; Turnipseed et al., 2001) and generally agree well with observed values. Also plotted are latent $(w q)$ and sensible $(w T)$ heat fluxes, which generally follow the VOC emission patterns. The upper panel in Fig. 7 depicts temperature and light with values ranging from $13-18^{\circ} \mathrm{C}$ and $300-1600$ PAR on both days.

Averaged data for a 4 day, fair weather period (14-17 June) are shown in Fig. 8 (upper left panel), with peak fluxes around $1.5 \mathrm{mg} \mathrm{m}^{-2} \mathrm{~h}^{-1}$, which is slightly higher (50\%) than the peak values reported by Baker et al. (2001). The reason could be that peak fluxes typically occurred between 12:00 and 14:00 LT, while no measurements were done in mid-July 1999 with roughly similar conditions (tempera- 
Table 1. VOC fluxes regressed against sensible heat $(w T)$ and latent heat fluxes $(w q)$, temperature $(T)$ and two linear models (GLM1, GLM2) using temperature and light (PAR) levels

\begin{tabular}{|c|c|c|c|}
\hline & VOC fluxes $\left[\mathrm{g} / \mathrm{m}^{2} \mathrm{~h}\right]$ & fitted model & $R$ \\
\hline \multirow[t]{4}{*}{$w T$} & $\mathrm{MBO}$ & $5.0 \times 10^{-4}+2.5 \times 10^{-6} \times \mathrm{wT}\left[\mathrm{W} \mathrm{m}{ }^{-2}\right]$ & 0.88 \\
\hline & methanol & $4.4 \times 10^{-4}+1.5 \times 10^{-6} \times \mathrm{wT}\left[\mathrm{W} \mathrm{m}{ }^{-2}\right]$ & 0.95 \\
\hline & acetaldehyde & $2.3 \times 10^{-4}+3.3 \times 10^{-7} \times \mathrm{wT}\left[\mathrm{W} \mathrm{m}{ }^{-2}\right]$ & 0.53 \\
\hline & acetone & $3.5 \times 10^{-4}+9.6 \times 10^{-7} \times \mathrm{wT}\left[\mathrm{W} \mathrm{m}{ }^{-2}\right]$ & 0.83 \\
\hline \multirow[t]{4}{*}{$w q$} & $\mathrm{MBO}$ & $8.6 \times 10^{-5}+4.6 \times 10^{-6} \times w q\left[\mathrm{~W} \mathrm{~m}^{-2}\right]$ & 0.80 \\
\hline & methanol & $2.2 \times 10^{-4}+2.6 \times 10^{-6} \times \mathrm{wq}\left[\mathrm{W} \mathrm{m}{ }^{-2}\right]$ & 0.80 \\
\hline & acetaldehyde & $1.9 \times 10^{-4}+5.2 \times 10^{-7} \times \mathrm{wq}\left[\mathrm{W} \mathrm{m}{ }^{-2}\right]$ & 0.41 \\
\hline & acetone & $1.9 \times 10^{-4}+1.8 \times 10^{-6} \times \mathrm{wq}\left[\mathrm{W} \mathrm{m}{ }^{-2}\right]$ & 0.75 \\
\hline \multirow[t]{4}{*}{$T$} & $\mathrm{MBO}$ & $\exp \left(-9.3+0.186 \times \mathrm{T}\left[{ }^{\circ} \mathrm{C}\right]\right)$ & 0.49 \\
\hline & methanol & $\exp \left(-7.3+0.0064 \times \mathrm{T}\left[{ }^{\circ} \mathrm{C}\right]\right)$ & 0.02 \\
\hline & acetaldehyde & $\exp \left(-10.2+0.161 \times \mathrm{T}\left[{ }^{\circ} \mathrm{C}\right]\right)$ & 0.58 \\
\hline & acetone & $\exp \left(-8.9+0.109 \times \mathrm{T}\left[{ }^{\circ} \mathrm{C}\right]\right)$ & 0.38 \\
\hline G & $\mathrm{MBO}$ & $\left(1.0+0.0067 \times \operatorname{PAR}\left[\mu \mathrm{mol} \mathrm{m}^{-2} \mathrm{~s}^{-1}\right]+4.2 \times \exp \left(\mathrm{T}-13.7\left[{ }^{\circ} \mathrm{C}\right]\right)\right) \times 10^{-4}$ & 0.84 \\
\hline $\mathrm{L}$ & methanol & $\left(3.4+0.0038 \times \operatorname{PAR}\left[\mu \mathrm{mol} \mathrm{m}^{-2} \mathrm{~s}^{-1}\right]-0.15 \times \exp \left(\mathrm{T}-13.7\left[{ }^{\circ} \mathrm{C}\right]\right)\right) \times 10^{-4}$ & 0.53 \\
\hline M & acetaldehyde & $\left(1.36+0.0087 \times \operatorname{PAR}\left[\mu \mathrm{mol} \mathrm{m}^{-2} \mathrm{~s}^{-1}\right]+1.45 \times \exp \left(\mathrm{T}-13.7\left[{ }^{\circ} \mathrm{C}\right]\right)\right) \times 10^{-4}$ & 0.53 \\
\hline 1 & acetone & $\left(1.73+0.0027 \times \operatorname{PAR}\left[\mu \mathrm{mol} \mathrm{m}{ }^{-2} \mathrm{~s}^{-1}\right]+1.87 \times \exp \left(\mathrm{T}-13.7\left[{ }^{\circ} \mathrm{C}\right]\right)\right) \times 10^{-4}$ & 0.79 \\
\hline G & MBO & $\left(-6.8+0.0068 \times \operatorname{PAR}\left[\mu \mathrm{mol} \mathrm{m}^{-2} \mathrm{~s}^{-1}\right]+0.757 \times \mathrm{T}\left[{ }^{\circ} \mathrm{C}\right]\right) \times 10^{-4}$ & 0.77 \\
\hline $\mathrm{L}$ & methanol & $\left(9.2+0.0045 \times \operatorname{PAR}\left[\mu \mathrm{mol} \mathrm{m}{ }^{-2} \mathrm{~s}^{-1}\right]-0.525 \times \mathrm{T}\left[{ }^{\circ} \mathrm{C}\right]\right) \times 10^{-4}$ & 0.61 \\
\hline M & acetaldehyde & $\left(-2.3+0.0008 \times \operatorname{PAR}\left[\mu \mathrm{mol} \mathrm{m}{ }^{-2} \mathrm{~s}^{-1}\right]+0.347 \times \mathrm{T}\left[{ }^{\circ} \mathrm{C}\right]\right) \times 10^{-4}$ & 0.46 \\
\hline 2 & acetone & $\left(-0.8+0.0029 \times \operatorname{PAR}\left[\mu \mathrm{mol} \mathrm{m}^{-2} \mathrm{~s}^{-1}\right]+0.249 \times \mathrm{T}\left[{ }^{\circ} \mathrm{C}\right]\right) \times 10^{-4}$ & 0.69 \\
\hline
\end{tabular}

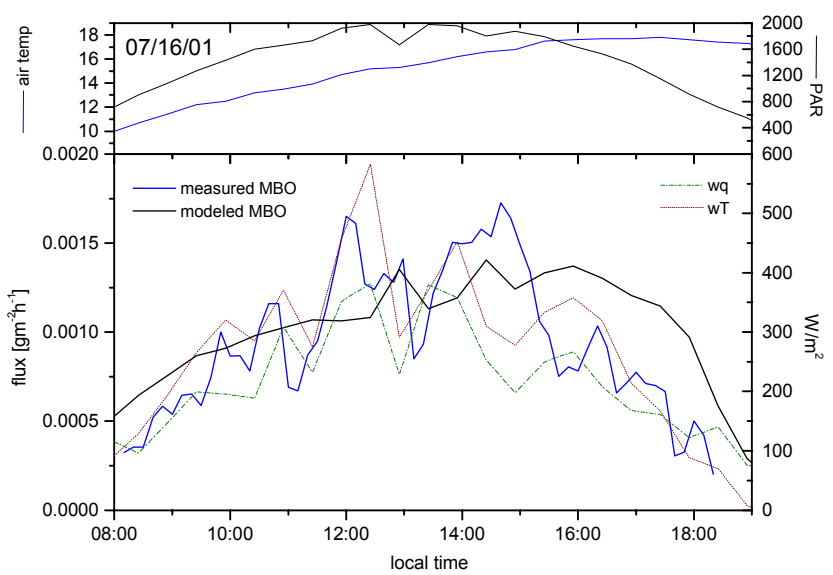

Fig. 7a. Lower Panel: Diurnal variation of MBO fluxes on 16 July, plotted together with modeled estimates and latent and sensible heat fluxes. Upper Panel: ambient air temperature and photosynthetically active radiation (PAR).

ture and light). It is noted that MBO fluxes obtained from this work will give an upper limit due to potential interferences and the fluxes reported by Baker et al. (2001) may be a lower limit due to their sample storage on cartridges which are susceptible to dehydration (loss) of MBO. How-

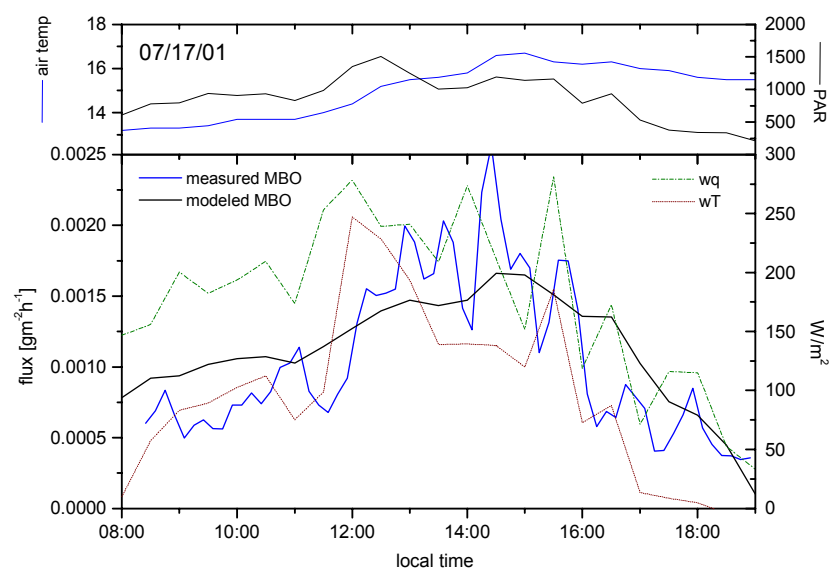

Fig. 7b. Lower Panel: Diurnal variation of MBO fluxes on 17 July, plotted together with modeled estimates and latent and sensible heat fluxes. Upper Panel: ambient air temperature and photosynthetically active radiation (PAR).

ever the observed difference in MBO fluxes lies within expected experimental errors and generally agrees well. The diurnal profiles for methanol, acetone and acetaldehyde fluxes are plotted in Fig. 8 (lower right, lower left and upper right panel) with peak values around $1,0.8$ and $0.4 \mathrm{mg} \mathrm{m}^{-2} \mathrm{~h}^{-1}$, 


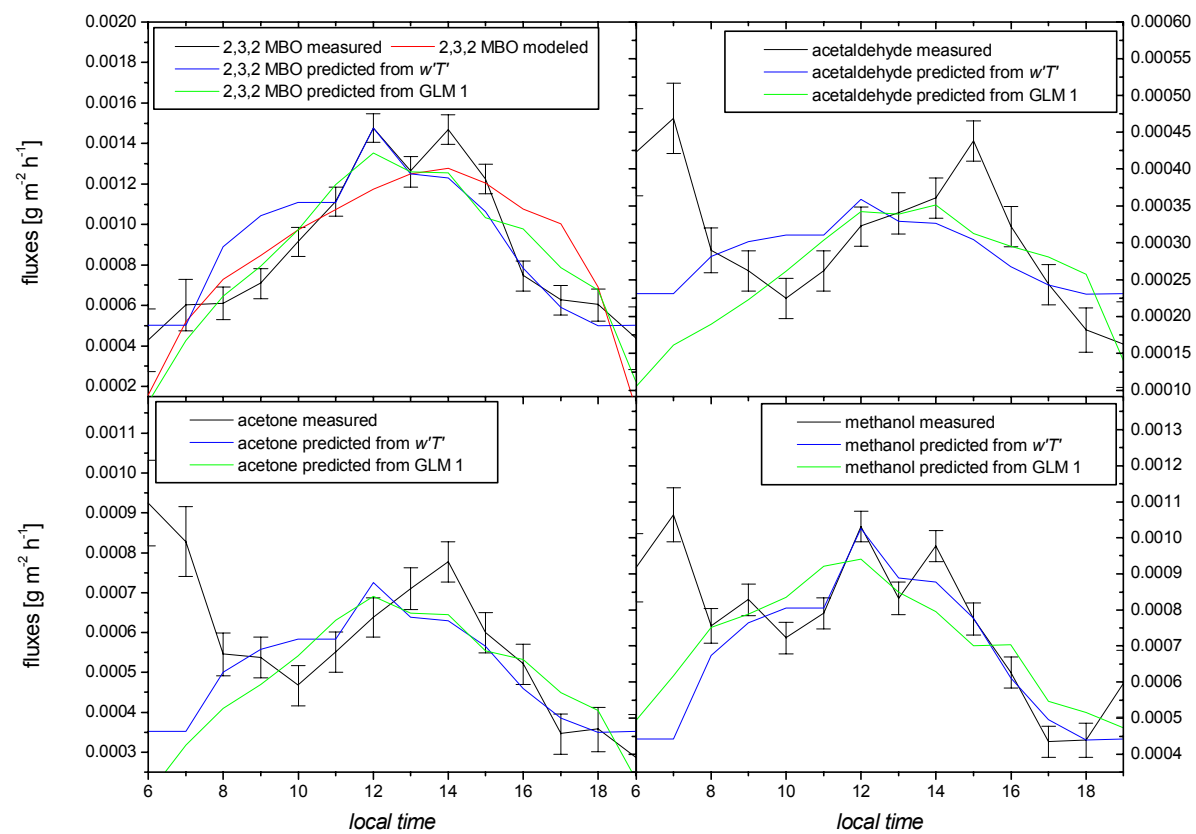

Fig. 8. Averaged diurnal VOC flux profiles measured on 14-17 July 2001; also plotted are VOC flux predictions from $w T$ (blue line) and GLM1 (green line) and model estimates (EXP96 algorithm) for $\mathrm{MBO}$ (red line). respectively. Baker et al. (2001) measured similar values for methanol $\left(1 \mathrm{mg} \mathrm{m}^{-2} \mathrm{~h}^{-1}\right)$ and 3 times higher acetone fluxes $\left(2.5 \mathrm{mg} \mathrm{m}^{-2} \mathrm{~h}^{-1}\right)$, which could be related to interannual or seasonal variability. Schade and Goldstein (2001) reported peak fluxes of MBO and methanol (2.1 and $4 \mathrm{mg} \mathrm{m}^{-2} \mathrm{~h}^{-1}$ ) in a ponderosa pine forest, which are higher than observed in this study. This is most likely related to temperature differences. Their measured acetaldehyde and acetone fluxes $(0.25$ and $0.4 \mathrm{mg} \mathrm{m}^{-2} \mathrm{~h}^{-1}$ ) are lower than the values seen here. The afternoon peak fluxes at Niwot Ridge coincided with the MBO maximum and are most likely due to maximum daily temperature and light conditions. In contrast, fluxes of acetone, acetaldehyde and methanol seem to exhibit an early morning peak occurring between 06:00 and 09:00 LT. Friction velocities during the morning hours were typically greater than $0.3 \mathrm{~m} \mathrm{~s}^{-1}$, but still may not be suitable for micrometeorological flux measurements. VOC storage during night time and subsequent concentration build up within the shallow nocturnal boundary layer probably contributed to the observed early morning peaks but is not likely to be the entire cause. Wind directions on 14-17 June were predominantly from the west $\left(\sim 281 \pm 10^{\circ}\right)$ suggesting that the effect of a changing footprint was probably small. Another explanation for these early morning flux peaks could be related to dew and effects reported by Warneke et al. (1999), who observed that wetted plant material can release substantial amounts of some oxygenated compounds. Warneke et al. (2002) also measured an increase of methanol fluxes after a rain event above an alfalfa field. Thus rain, occurring during night time, together with dew formation could result in similar effects. In addition, experiments with lodgepole pine trees showed that increased light levels after a longer dark phase consistently resulted in acetone spikes (Baker, 2000; Karl 2000a).

A correlation between VOC fluxes and various parameters such as light, temperature, sensible heat and latent heat fluxes was performed and is summarised in Table 1. Data between 06:00 and 09:00 LT for methanol, acetone and acetaldehyde were excluded from this analysis due to the observed early morning spikes, which are most likely not related to those parameters. Best results were obtained between sensible heat and VOC fluxes as shown in Fig. 9, yielding correlation coefficients of 0.88 (MBO), 0.95 (methanol), 0.53 (acetaldehyde) and 0.83 (acetone). The relation between latent heat $(w q)$ and VOC fluxes is expectedly similar and only shows a slightly poorer correlation. An exponential dependence as proposed by Guenther et al. (1995) for purely temperature driven VOC emissions was fitted yielding $R$ between 0.4 and 0.6 for $\mathrm{MBO}$, acetaldehyde and acetone and very poor correlation for methanol $(R=0.02)$. The poor correlation was likely at least partly due to using ambient temperature, rather than leaf temperature, to drive the model. The light dependence of VOC fluxes seems to be more pronounced. Even better results were obtained by applying a general linear model (GLM) and regressing against temperature and light levels. Since fluxes were measured at a rather low and narrow temperature range $\left(13-18^{\circ} \mathrm{C}\right)$ below typical saturation points, linear fitting procedures gave the best results. The green and blue lines in Fig. 8 show predicted VOC fluxes at Niwot Ridge as inferred from the $w T$ and GLM regressions. Correlations observed between VOC fluxes and environmental parameters such as latent and sensible heat fluxes, which are routinely calculated in climate and land surface models such as the Community Land Model (CLM) and the Com- 


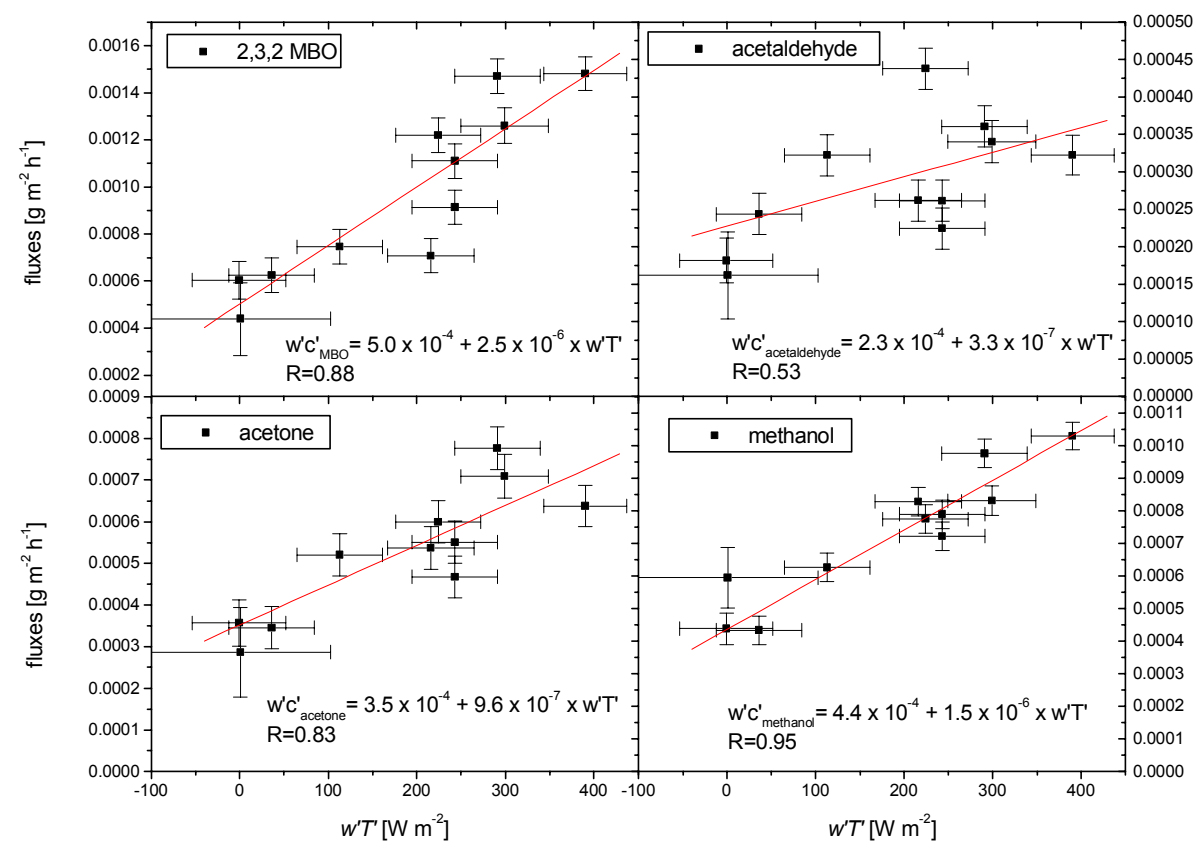

Fig. 9. VOC fluxes plotted versus sensible heat fluxes $(w T)$ for the 4 day averaged diurnal profiles between 14 and 17 July 2001. munity Climate System Model (CCSM) at NCAR, could potentially allow for these oxygenated compounds to be better estimated in emission models.

\subsection{Box model sensitivity analysis}

We performed a box model (0-D) sensitivity study to investigate the influence on oxidant levels in the troposphere due to the measured MBO, methanol, acetone and acetaldehyde emissions. The NCAR Master Mechanism (MM) (Madronich and Calvert, 1990; Hauglustaine et al., 1999; Aumont et al., 1999) was initiated at standard conditions including the basic hydrocarbon chemistry encountered at $\mathrm{Ni}$ wot Ridge (Greenberg and Zimmerman, 1984; Goldan et al., 1997) and CO obtained from continuous measurements made at the site. MBO chemistry was included in the model based on data published by Ferronato et al. (1998). The MM was initialised with and without biogenic emissions (as predicted from the diurnal $w T$ variation in Fig. 9) in order to look at the sensitivity on the model results. Water vapour was fixed at $2 \mathrm{~g} / \mathrm{kg}$ and model runs were performed at $\mathrm{NO}_{\mathrm{x}}$ levels ranging between 50 and 2000 pptv. Though the absolute $\mathrm{NO}_{\mathrm{x}}$ concentration was held fixed, the relative concentrations of $\mathrm{NO}$ and $\mathrm{NO}_{2}$ were allowed to vary in the model over the course of a day. The planetary nighttime boundary layer height was taken as $0.2 \mathrm{~km}$, ramping up to $1.5 \mathrm{~km}$ between 08:00 and 14:00 and decreasing back to $0.2 \mathrm{~km}$ between 16:00 and 18:00. Entrainment velocities around $2 \mathrm{~cm} \mathrm{~s}^{-1}$ estimated from the growth of the planetary boundary layer (PBL) were incorporated as a first order rate constant and constrained by measured ambient MBO concentrations. Limitations associated with photochemical box mod- elling and the model used here are discussed by Stevens et al. (1997), Eisele et al. (1997) and Greenberg et al. (1999); general aspects of zero-dimensional box modelling can also be found in McKeen et al. (1997).

The $\mathrm{OH}$ reactivity (first order loss rate) for the most important species considered here is dominated by MBO $\left(3.4 \mathrm{~s}^{-1}\right)$, followed by CO $\left(0.82 \mathrm{~s}^{-1}\right)$, methane $\left(0.32 \mathrm{~s}^{-1}\right)$, formaldehyde $\left(0.23 \mathrm{~s}^{-1}\right.$, derived from the model), acetaldehyde $\left(0.22 \mathrm{~s}^{-1}\right)$, terpenes (upper limit for this study: $\left.0.24 \mathrm{~s}^{-1}\right)$, olefins $\left(0.20 \mathrm{~s}^{-1}\right.$, adopted from Goldan et al., 1997; Greenberg and Zimmermann, 1984), methanol $\left(0.11 \mathrm{~s}^{-1}\right)$, acetone $\left(0.01 \mathrm{~s}^{-1}\right)$ and aromatics $\left(0.04 \mathrm{~s}^{-1}\right)$. It is noted that acetone can also be photochemically produced from MBO oxidation with a 54\% molar yield. Taking the reaction rate with $\mathrm{HO}$ (kMBO $\sim 7 \times 10^{-11} \mathrm{~cm}^{3} \mathrm{~s}^{-1}$ ), HO concentrations in the range of $1-4 \times 10^{6}$ molecules $\mathrm{cm}^{-3}$ and typical surface layer timescales, $\tau_{s} \sim 50-200 \mathrm{~s}$, observed during this study, $\sim 1-5 \%$ of the observed acetone flux can be derived from the oxidation of MBO. However, in-canopy $\mathrm{NO}_{3}$ and/or $\mathrm{O}_{3}$ chemistry could potentially increase this amount.

Peak HO concentrations occur around noon (12:00-14:00) and are for example as high as $1.3 \times 10^{7}$ molecules $\mathrm{cm}^{-3}$ without and $3.7 \times 10^{6}$ molecules $\mathrm{cm}^{-3}$ with VOC emissions turned on at 400 pptv $\mathrm{NO}_{\mathrm{x}}$. The HO peak is shifted by approximately $2 \mathrm{~h}$ when VOC emissions are added into the model; this is mainly due to the fact that peak VOC fluxes are typically observed in the early afternoon. Peroxy radicals are significantly enhanced by the ongoing production from the oxygenated hydrocarbon (mainly 2,3,2 MBO) chemistry and peak around noon. Relative changes of ozone, PAN, HO concentrations and $\mathrm{HO}_{2} / \mathrm{RO}_{2}$ ratios (upper left, lower left, 

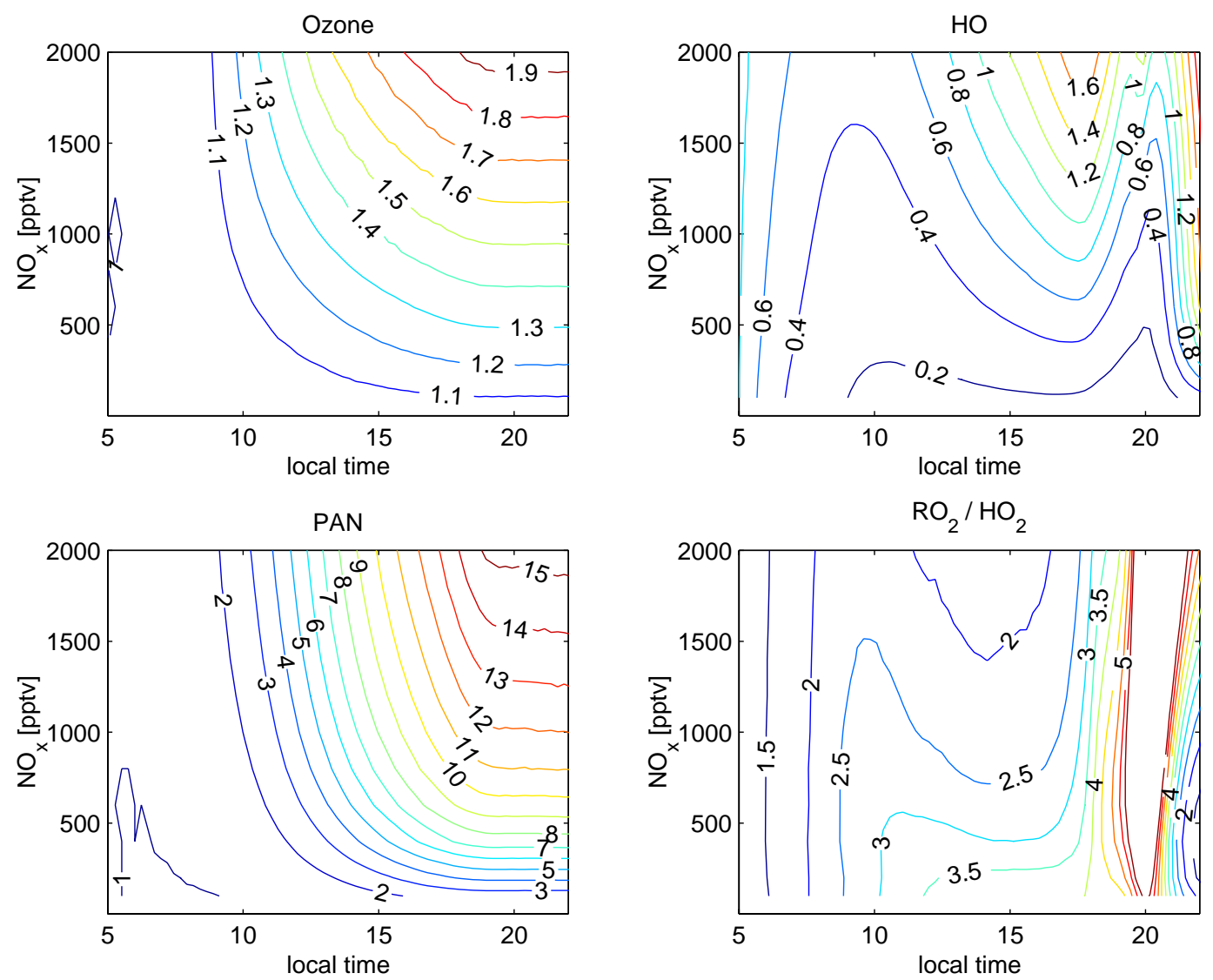

Fig. 10. Results from a 0-D box model sensitivity study. Plotted are the ratios of ozone, $\mathrm{PAN}, \mathrm{HO}$ and $\mathrm{HO}_{2} / \mathrm{RO}_{2}$ with and without VOC emissions turned on as a function of $\mathrm{NO}_{\mathrm{x}}$ concentrations and local time.

upper right and lower right panel) due to VOC emissions as a function of $\mathrm{NO}_{\mathrm{x}}$ levels are shown in a contour plot (Fig. 10). $\mathrm{NO}_{\mathrm{x}}$ levels were based on measurements done by Parrish et al. (1984) and Ridley et al. (1990). Parrish et al. (1984) reported substantial $\mathrm{NO}_{\mathrm{x}}$ concentrations at the site during a previous year with a median between $400-600$ pptv (at noon) during the months of June, July and August and conclude that "even though the Denver urban area lies upwind from the site with respect to the prevailing winds, it is $\mathrm{NO}_{\mathrm{x}}$ from the Niwot Ridge area that predominates and is responsible for enhanced ozone levels at the site". For clean westerly conditions $\left(\sim 100-300\right.$ pptv $\left.\mathrm{NO}_{\mathrm{x}}\right)$ ozone is enhanced by $10-20 \%$, PAN by a factor of $2-5, \mathrm{RO}_{2} / \mathrm{HO}_{2}$ up to a factor of $\sim 5$ and $\mathrm{HO}$ is reduced to $20 \%$ in the afternoon. Similarily acetone and methanol concentrations in the box are enhanced by a factor of 5 during midday. This shows that secondary photochemical generation of methanol (methane oxidation) plays a minor role when compared to the dominant local biogenic emission. The same holds for acetone, which has a strong local source due to direct emissions and the oxidation of MBO (up to $\sim 5 \%$ ). Both compounds are relatively long-lived and can be transported into the upper troposphere, where they are readily photolysed and present an important source for per- oxy radical formation.

Discrepancies between measured and calculated $\mathrm{HO}_{2} / \mathrm{HO}$ and $\mathrm{HO}_{2} / \mathrm{RO}_{2}$ ratios during the tropospheric $\mathrm{OH}$ Photochemistry Experiment were mainly traced back to the rate constant of the $\mathrm{RO}_{2}+\mathrm{NO}$ reaction (Stevens et al., 1997). However, even with an adapted rate constant for the $\mathrm{RO}_{2}$ + NO reaction modeled vs. measured $\mathrm{HO}_{2} / \mathrm{RO}_{2}$ ratios did not agree very well. Cantrell et al.(1997) speculate about interferences in the peroxy-radical measurements or some unknown radical production mechanisms that would cause modeled and measured $\mathrm{HO}_{2} / \mathrm{RO}_{2}$ ratios to be off by a factor of 4-10. Results obtained here demonstrate the sensitivity on local biogenic VOC emissions, which for example increase modeled $\mathrm{HO}_{2} / \mathrm{RO}_{2}$ ratios by a factor of $\sim 5$, falling close to measured values during the tropospheric $\mathrm{OH}$ Photochemistry Experiment at low $\mathrm{NO}_{\mathrm{x}}$ conditions. In order to explain the discrepancy between measured and modeled $\mathrm{OH}$ concentrations, McKeen et al. (1997) speculate about an unkown VOC source not measured during the $\mathrm{OH}$ Photochemistry Experiment. On the other hand their model results underestimated acetaldehyde levels by a factor of four, since mainly $\mathrm{C}_{2} \mathrm{H}_{6}$ oxidation was considered as the primary source under clean conditions. They speculate that the oxidation of monoter- 
penes (e.g. $\alpha$-pinene) could lead to increased acetaldehyde concentrations; however taking observed monoterpene concentrations ( $<100$ pptv) from Goldan et al. (1997) most of their observed acetaldehyde abundancy could still not be accounted for. Here we see fluxes of acetaldehyde with peak values up to $\sim 0.4 \mathrm{mg} \mathrm{m}^{-2} \mathrm{~h}^{-1}$ (concentrations up to $2 \mathrm{ppbv}$ ). This represents a substantial amount emitted directly by the forest and could account for discrepancies observed in earlier studies. The total measured monoterpene concentration was typically less than $100 \mathrm{pptv}$. Thus, primary emissions by the vegetation is thought to be the major source, even though a small amount can be derived from the oxidation of monoterpenes within the canopy. As PAN is mainly generated from $\mathrm{CH}_{3} \mathrm{COO}_{2}$ radicals, acetaldehyde decomposition is it's major source in the present study. PAN levels due to the formation from primary (forest emissions) and potentially secondary acetaldehyde sources (e.g. terpene oxidation) peak around 16:00 $\left(\sim 2.1 \times 10^{10}\right.$ molecules $\mathrm{cm}^{-3} ; \sim 800 \mathrm{pptv}$ at 400 pptv $\mathrm{NO}_{\mathrm{x}}$ ) and together with peroxy radicals illustrate the overall photochemical activity in the PBL. Peak concentrations of PAN scaled down to $\sim 400$ pptv at 200 pptv $\mathrm{NO}_{\mathrm{x}}$ and to $\sim 190 \mathrm{pptv}$ at $100 \mathrm{pptv} \mathrm{NO}_{\mathrm{x}}$ and lie within the range observed by Ridley et al. (1990).

The sensitivity study demonstrates that without detailed quantitative knowledge of biogenic VOC emissions from the forest the modelled HO, PAN and peroxy radical concentrations as well as $\mathrm{RO}_{2} / \mathrm{HO}_{2}$ ratios are significantly underestimated in both westerly and easterly winds. In addition ozone enhancment can exceed $40 \%$ at high $\mathrm{NO}_{\mathrm{x}}$ levels $(\sim 1 \mathrm{ppbv})$; locally produced VOCs can therefore add a substantial amount of 'fuel' and contribute to the high ozone concentrations observed at the Niwot Ridge site.

\section{Conclusions}

This paper describes the first experimental tests of the concept of virtual disjunct eddy covariance (vDEC) for field measurements of VOC fluxes. A PTR-MS instrument was used as the VOC sensor. VOC losses through long lines frequently encountered with canopy level flux measurements seem to be mainly governed by diffusion laws. Results from a wind tunnel experiment demonstrated that for the setup used in this work ( $50 \mathrm{~m}$ line (i.d. $\left.1 / 4^{\prime \prime}\right)$, flow rate of $15 \mathrm{l} / \mathrm{min}$ ) the half power frequency $f_{1 / 2}$ was typically around $5.5 \mathrm{~Hz}$, still high enough to avoid significant bias in the vDEC measurements. In addition, coiled lines improved the spectral attenuation by stabilising the flow in the tube. We observed significant fluxes of MBO, methanol, acetone and acetaldehyde at a subalpine forest site governed by a short growing season and cool temperatures. MBO emission estimates modelled with the EXP96 algorithm (Guenther et al., 1999) were in reasonable agreement with measured values. In addition, sensible heat fluxes $(w T)$ appeared to be the best predictor of daytime VOC emissions observed during this study.
Therefore sensible and latent heat flux ( $w T$ and $w q$ ) relationships could be used to model MBO, acetone, acetaldehyde and methanol emissions, as opposed to the 'traditional light and temperature algorithms'.

Box model simulations indicated that oxidant levels, such as $\mathrm{HO}(-70 \%), \mathrm{HO}_{2}(+50 \%)$, PAN (+800 pptv) and $\mathrm{O}_{3}$ $(+23 \%)$, are significantly changed due to the release of $\mathrm{MBO}$, methanol, acetone and acetaldehyde by the forest. These compounds therefore play a crucial role in the local and regional atmospheric chemistry. Comparison with observed PAN concentrations at the Niwot Ridge site (Ridley et al., 1990) shows that without biogenic VOC emissions the modelled PAN levels are almost one order of magnitude lower than observations. Biogenic emission models do not usually predict speciated emissions of oxygenated compounds; especially for the case of some important key compounds, such as acetaldehyde, this plays a nontrivial role in terms of the ambient photochemistry. The modelling sensitivity study done as part of this paper shows that incorrect model predictions can result when these emissions are not included.

Future work at the site involving nitrogen containing species, such as $\mathrm{NO}_{\mathrm{x}}$ and $\mathrm{NO}_{\mathrm{y}}$, together with long term VOC and aerosol flux measurements could be used to model the chemistry more accurately, e.g. differentiate the Denver plume from local disturbances, and provide a unique data set describing the chemical forest-atmosphere interaction. We conclude that vDEC with a PTR-MS instrument is a versatile tool for simultaneous field analysis of multiple VOC fluxes.

\section{Appendix: Error Analysis}

(1) The systematic error of the flux $F$ measured by disjunct sampling due to the finite samples during one averaging period can be approximated by:

$$
\begin{gathered}
\frac{F-\langle F(T, \Delta x)\rangle}{F} \cdot \frac{T}{l_{w s}}=\frac{\Delta x}{l_{w s}}\left\{\operatorname{coth}\left(\frac{\Delta x}{2 l_{w s}}\right)\right. \\
\left.-\frac{\left(\Delta x / l_{w s}\right) \cdot\left(l_{w s} / T\right)-\left[1-\exp \left(-T / l_{w s}\right)\right]}{2 \cdot \sinh ^{2}\left(\Delta x / 2 l_{w s}\right)}\right\}
\end{gathered}
$$

with $l_{w s}$ (integral time scale), $T$ (averaging period), $\Delta x$ (sampling interval). (Lenschow et al., 1994). In the present case we infer (see Sect. 2.2) a systematic error of $\sim 1.1 \%$.

(2) Wesely and Hart (1985) discuss errors encountered due to geophysical variability. They indicate that for neutral and unstable conditions these can be approximated by:

$$
\begin{array}{ll}
\frac{\delta F}{F}=\sqrt{\frac{12 \cdot z}{T \cdot u}} & \text { unstable } \\
\frac{\delta F}{F}=\sqrt{\frac{20 \cdot z}{T \cdot u}} & \text { neutral }
\end{array}
$$

with $T$ (averaging period: $30 \mathrm{~min}$ ), $z$ (height above ground) and $u$ (wind speed). Taking $u=4 \mathrm{~m} / \mathrm{s}, z=10 \mathrm{~m}$ above 
the canopy and $T=1800 \mathrm{~s}$, we infer an error of $13 \%$ for unstable and $17 \%$ for neutral conditions.

(3) Random errors for VOC concentrations can be described by counting statistics according to the Poisson distribution:

$$
\frac{\delta C}{C}=\frac{1}{\sqrt{S \cdot C \cdot T}}
$$

with $C$ (concentration), $S$ (sensitivity $\mathrm{Hz} / \mathrm{ppbv}$ ), and $T$ (averaging period). With $C \sim 500 \mathrm{pptv}, S=100 \mathrm{~Hz} / \mathrm{ppbv}$ and $T=1800 \mathrm{~s}$, the random error (white noise) of the concentration measurement is $0.3 \%$.

(4) Systematic errors for the determination of the VOC concentrations can be described as,

$$
\frac{\delta C}{C}=\frac{\delta k}{k}+\frac{\delta t_{r}}{t_{r}}
$$

with $C$ (concentration), $k$ (reaction rate constant), and $t_{r}$ (reaction time in the drift tube), and are $\sim 20 \%$ mainly due to uncertainties of $k$. In the present case we calibrated the system by running a dilution curve of a high concentration VOC standard with an estimated uncertainty of $10 \%$.

Acknowledgements. Dedicated to the memory of our colleague Werner Lindinger. The authors also want to thank T. Märk and A. Hansel for continuing support, D. Lenschow, A. Cooper and Christine Wiedinmyer for fruitful discussions and A. Turnipseed, R. Monson, B. Baugh and P. Harley for their help in running the Ameriflux tower site. TK was supported by funds from the Advanced Study Program and the Atmospheric Chemistry Division at the National Center for Atmospheric Research. The National Center for Atmospheric Research is sponsored by the National Science Foundation. This research was also supported in part by NSF grant ATM-9805191 and NOAA grant (NA06GP0483) to the U. Colorado and by an Interagency Agreement (DW49939559) with the National Risk Management Research Laboratory of the U.S. Environmental Protection Agency; we thank Chris Geron for his support as project officer.

\section{References}

Atkinson, R.: Gas-phase tropospheric chemistry of organic compounds, American Chemical Society ; Woodbury, N.Y.: American Institute of Physics, for the National Institute of Standards and Technology, 1994.

Aumont, B., Madronich, S., Ammann, M., Baltensperger, E., Hauglustaine, D., and Brocheton, F.: On the $\mathrm{NO}_{2}$ soot reaction in the atmosphere, J. Geophys. Res., 104, 1729-1736, 1999.

Baker, J. M., Norman, J. M., and Bland, W. L.: Field-scale application of flux measurement by conditional sampling. Agric. For. Meteorol., 62, 31-52, 1992.

Baker, B., Guenther, A., Greenberg, J., and Fall, R.: Canopy Level Fluxes of 2-metyl-3-buten-2-ol, acetone and methanol by a portable relaxed eddy accumulation system, Environ. Sci. Techn., 35, 1701-1708, 2001.

Baker, B.: Ph.D. Thesis, University of Colorado, 2000.

Businger, J. A. and Oncley, S. P.: Flux measurement with conditional sampling, J. Atmos. Oceanic Technol., 7, 349-352, 1990.
Cantrell, C. A., Shetter, R. E., Calvert, J. G., Eisele, F. L., Williams, E., Baumann, K., Brune, W. H., and Stevens, P. S.: Peroxy radicals from photostationary state deviations and steady state calculations during the Tropospheric $\mathrm{OH}$ Photochemistry Experiment at Idaho Hill, Colorado, 1993, J. Geophys. Res., 102, 6369-6379, 1997.

Dabberdt, W. F., Lenschow, D. H., Horst, T. W., Zimmerman, P. R., Oncley, S. P., and Delany, A. C.: Atmosphere-surface exchange measurements, Science, 260, 1472-1482, 1993.

de Gouw, J., Warneke, C., Karl, T., Eerdekens, G., van der Veen, C., and Fall, R.: Sensitivity and specificity of atmospheric trace gas detection by Proton-Transfer-Reaction Mass Spectrometry, Int. Journal for Mass Spectrometry, in press, 2002.

Eckert, E. R. G. and Drake, R. M.: Heat and Mass Transfer, pp. 530, McGraw-Hill, New York, 1959.

Eisele, F. L., Mount, G. H., Tanner, D., Jefferson, A., Shetter, R., Harder, J. W., and Williams, E. J.: Understanding the production and interconversion of the hydroxyl radical during the Tropospheric OH Photochemistry Experiment, J. Geophys. Res., 102, 6457-6465, 1997.

Ferronato, C., Orlando, J. J., and Tyndall, G. S.: Rate and mechanism of the reactions of $\mathrm{OH}$ and $\mathrm{Cl}$ with 2-methyl-3-buten-2-ol, J. Geophys. Res., 103, 25 579-25 586, 1998.

Fuentes, J. D., Wang, D., Neumann, H. H., Gillespie, T. J., Den Hartog, G. and Dann, T. F.: Ambient biogenic hydrocarbons and isoprene emissions from a mixed deciduous forest. J. Atmos. Chem., 25, 67-95, 1996.

Goldan, P. D., Kuster, W. C., Fehsenfeld, F. C., and Montzka, S. A.: The observation of $\mathrm{a} \mathrm{C}_{5}$ alcohol emission in a north-american pine forest, J. Geophys. Res., 20, 1039-1042, 1993.

Goldstein, A. H., Fan, S. M., Goulden, M. L., Munger, J. W., and Wofsy, S. C.: Emissions of ethene, propene and 1-butene by a midlatitude forest, J. Geophys. Res., 101, 9149-9157, 1996.

Granier, C., Brasseur, G., and Erickson, D.: Atmospheric Chemistry and Climate, In: Atmospheric Chemistry and Global Change, (Eds) Brasseur, G., Orlando, J., and Tyndall, G., John Wiley and Sons, New York, 1998.

Greenberg, J. P., Guenther, A. B., Madronich, S., Baugh, W., Ginoux, P., Druilhet, A., Delmas, R., and Delon, C.: Biogenic volatile organic compound emissions in central Africa during the Experiment for the Regional Sources and Sinks of Oxidants (EXPRESSO) biomass burning season, J. Geophys. Res., 104, 30 659-30 671, 1999.

Greenberg, J. P. and Zimmerman, P. R.: Nonmethane Hydrocarbons in Remote Tropical, Continental, and Marine Atmospheres, J. Geophys. Res., 89, 4767-4778, 1984.

Guenther, A., Hewitt, C. N., Erickson, D., Fall, R., Geron, C., Graedel, T., Harley, P., Klinger, L., Lerdau, M., McKay, W. A., Pierce, T., Scholes, B., Steinbrecher, R., Tallamraju, R., Taylor, J., and Zimmerman, P.: A global model of natural volatile organic compound emissions, J. Geophys. Res., 100, 8873-8892, 1995.

Guenther, A., Baugh, W., Davis, K., Hampton, G., Harley, P., Klinger, L., Vierling, L., Zimmerman, P., Allwine, E., Dilts, S., Lamb, B., Westberg, H., Baldocchi, D., Geron, C., and Pierce, T.: Isoprene fluxes measured by enclosure, relaxed eddy accumulation, surface layer gradient, mixed layer gradient, and mixed layer mass balance techniques, J. Geophys. Res., 101, 18555 18 567, 1996. 
Guenther, A., Baugh, B., Brasseur, G., Greenberg, J., Harley, P., Klinger, L., Serca, D., and Vierling, L.: Isoprene emission estimates and uncertainties for the Central African Expresso study domain, J. Geophys. Res., 104, 30 625-30 639, 1999.

Guenther, A. and Hills, A. J.: Eddy covariance measurement of isoprene fluxes, J. Geophys. Res., 103, 13 145-13 152, 1998.

Guenther, A.: Trace gas emission measurements, in: Environmental monitoring Handbook, (Eds) Burden et al., McGraw-Hill. ISBN 0071-35-1760, 24, 1-18, 2002.

Harley, P., Fridd-Stroud, V., Greenberg, J., Guenther, A., and Vasconcellos, P.: Emission of 2-methyl-3-buten-2-ol by pines: A potentially large natural source of reactive carbon to the atmosphere, J. Geophys. Res., 103, 25 479-25 486, 1998.

Hauglustaine, D. A., Madronich, S., Ridley, B. A., Flocke, S. J., Cantrell, C. A., Eisele, F. L., Shetter, R. E., Tanner, D. J., Ginoux, P., and Atlas, E. L.: Photochemistry and budget of ozone during the Mauna Loa Observatory Photochemistry Experiment (MLOPEX 2), J. Geophys. Res., 104, 30 275-30 307, 1999.

Kaimal, J. C., Wyngaard, J. C., Izumi, Y., and Cote, O. R.: Spectral characteristics of surface layer turbulence, Q. J. R. Meteorol. Soc., 98, 563-589, 1972.

Karl, T.: Ph.D. Thesis, University of Innsbruck, 2000a.

Karl, T., Guenther, A., Jordan, A., Fall, R., and Lindinger, W.: Eddy covariance measurement of biogenic oxygenated VOC emissions from hay harvesting, Atmos. Environ., 35, 491-495, 2000b.

Karl, T., Fall, R., Crutzen, P. J., Jordan, A., and Lindinger, W.: High concentrations of reactive biogenic VOCs in the free troposphere during late autumn, Geophys. Res. Lett., 28, 507-510, 2001.

Kesselmeier, J.: Exchange of short-chain oxygenated volatile organic compounds (VOCs) between plants and the atmosphere: A compilation of field and laboratory studies, J. Atmos. Chem., 39, 219-233, 2001.

Koenig, G., Brunda, M., Puxbaum, H., Hewitt, C. N., Duckham, S. C., and Rudolph, J.: Relative contribution of oxygenated hydrocarbons to the total biogenic VOC emissions of selected mideuropean agricultural and natural plant-species, Atmos. Environ., 29, 861-874, 1995.

Lenschow, D. H. and Kristensen, L.: Uncorrelated noise in turbulence measurements, J. Atmos. Oceanic Tech., 2, 68-81, 1985.

Lenschow, D. H. and Raupach, M. R.: The attenuation of fluctuations in scalar concentrations throurgh sampling tubes, J. Geophys. Res., 96, 15 259-15 268, 1991.

Lenschow, D. H., Mann, J., and Kristensen, L.: How long is long enough when measuring fluxes and other turbulence statistics?, J. Atmos. Oceanic Tech., 11, 661-673, 1994.

Lindinger, W., Hansel A., and Jordan, A.: On-line monitoring of volatile organic compounds at pptv levels by means of ProtonTransfer-Reaction Mass Spectrometry (PTR-MS). Medical applications, food control and environmental research, Int. J. Mass Spectrom. Ion Proc., 173, 191-241, 1998.

Madronich, S. and Calvert, J. G.: Permutation reactions of organic peroxy radicals in the troposphere, J. Geophys. Res., 95, 56975715,1991

Massman, W. J.: The attenuation of concentration fluctuations in turbulent flow through a tube, J. Geophys. Res., 96, 15269 15273,1991

McConalogue, D. J.: The effects of secondary flow on the laminar dispersion of an injected substance in a curved tube, Proc. R. Soc. London A. Ser., 315, 99-113, 1970.
McKeen, S. A., Mount, G., Eisele, F., Williams, E., Harder, J., Goldan, P., Kuster, W., Liu, S. C., Baumann, K., Tanner, D., Fried, A., Sewell, S., Cantrell, C., and Shetter, R.; Photochemical modeling of hydroxyl and ist realtionship to other species during the Tropospheric OH Photochemistry Experiment, J. Geophys. Res., 102, 6467-6493, 1997.

McMillen, R. T.: An Eddy Correlation Technique with Extended Applicability to Non-simple Terrain, Boundary-Layer Meteorol., 43, 231-245, 1988

Ridley, B. A., Shetter, J. D., Walega, J. G., Madronich, S., Elsworth, C.M., Grahek, F. E., Fehsenfeld, F. C., Norton, R. B., Parrish, D. D., Huebler, G., Buhr, M., Williams, E. J., Allwine, E. J., and Westberg, H. H.: The behavior of some organic nitrates at Boulder and Niwot Ridge, Colorado, J. Geophys. Res., 95, 13949 $13961,1990$.

Rinne, H. J. I., Guenther, A., Warneke, C., de Gouw, J. A., and Luxembourg, S. L.: Disjunct eddy covariance technique for trace gas flux measurements, Geophys. Res. Lett., 28, 3139-3142, 2001.

Rinne, H. J. I., Delany, A. C., Greenberg, J. P., and Guenther, A. B.: A true eddy accumulation system for trace gas fluxes using disjunct eddy sampling method, J. Geophys. Res., 105, $24791-$ 24 798, 2000.

Schade, G. W. and Goldstein, A. H.: Fluxes of oxygenated volatile organic compounds from a ponderosa pine plantation, J. Geophys. Res., 106, 3111-3123, 2001.

Shaw W. J., Spicer, C. W., and Kenny, D.: Eddy correlation fluxes of trace gases using a tandem mass spectrometer, Atmos. Environ., 32, 2887-2898, 1998.

Singh, H. B., Kanakidou, M., Crutzen, P. J., and Jacob, D. J.: High concentrations and photchemical fate of oxygenated hydrocarbons in the global troposphere, Nature, 378, 50, 1995.

Stevens, P. S., Mather, J. H., Brune, W. H., Eisele, F., Tanner, D., Jefferson, A., Cantrell, C., Shetter, R., Sewall, S., Fried, A., Henry, B., Williams, E., Baumann, K., Goldan, P., and Kuster, W.: $\mathrm{HO}_{2} / \mathrm{OH}$ and $\mathrm{RO}_{2} / \mathrm{HO}_{2}$ ratios during the Tropospheric $\mathrm{OH}$ Photochemistry Experiment: Measurement and theory, J. Geophys. Res., 102, 6379-6391, 1997.

Stull, R. B.: An Introduction to Boundary Layer Meteorology, Kluwer Acad. Publ., Dordrecht, 1988.

Tennekes, H. and Lumley, J. L.: A first course in turbuluence, pp. 300, MIT, Cambridge, 1972.

Turnipseed, A. A., Blanken, P. D., Anderson, D. E., and Monson, R. K.: Energy budget above a high-elevation subalpine forest in complex topography, Agricultural and Forest Meteorology, 110, 177-201, 2002.

Warneke, C., Karl, T., Judmaier, H., Hansel, A., Jordan, A., Lindinger, W., and Crutzen, P. J.: Acetone, methanol, and other partially oxidized volatile organic emissions from dead plant matter by abiological processes: Significance for atmospheric $\mathrm{HO}_{\mathrm{x}}$ chemistry, Global Biogeochem. Cycles, 13, 9-17, 1999.

Warneke, C., Luxembourg, S. L., de Gouw, J. A., Rinne, H. J. I., Guenther, A. B., and Fall, R.: Disjunct eddy covariance measurements of oxygenated VOC fluxes from an alfalfa field before and after cutting, J. Geophys. Res., 107, 2002.

Wesely, M. L. and Hart, R. L.: Variability of short term eddy-covariance estimates of mass exchange, in: The forestatmosphere interactions, (eds) Hutchison, B. and Hicks,B., D. Reidel publishing Company, Dortrecht, The Netherlands, 591$612,1985$. 